\title{
BMJ Open Clinical risk score to predict in-hospital mortality in COVID-19 patients: a retrospective cohort study
}

\section{Carlo Fumagalli (i) , ${ }^{1}$ Renzo Rozzini, ${ }^{2}$ Matteo Vannini, ${ }^{3}$ Flaminia Coccia, ${ }^{2}$ Giulia Cesaroni, ${ }^{2}$ Francesca Mazzeo, ${ }^{2}$ Maria Cola, ${ }^{4}$ Alessandro Bartoloni, ${ }^{1,4}$ Paolo Fontanari, ${ }^{3}$ Federico Lavorini, ${ }^{1,3}$ Rossella Marcucci, ${ }^{1,3}$ Alessandro Morettini, ${ }^{4}$ Carlo Nozzoli, ${ }^{4}$ Adriano Peris, ${ }^{5}$ Filippo Pieralli, ${ }^{4}$ Riccardo Pini, ${ }^{1,4}$ Loredana Poggesi, ${ }^{1,4}$ Andrea Ungar, ${ }^{1}$ Stefano Fumagalli, ${ }^{1}$ Niccolò Marchionni (D) ${ }^{1,3}$}

To cite: Fumagalli C, Rozzini R, Vannini $\mathrm{M}$, et al. Clinical risk score to predict in-hospital mortality in COVID-19 patients: a retrospective cohort study. BMJ Open 2020;10:e040729. doi:10.1136/ bmjopen-2020-040729

- Prepublication history for this paper is available online To view these files, please visit the journal online (http://dx.doi. org/10.1136/bmjopen-2020040729).

Received 20 May 2020 Revised 06 August 2020 Accepted 01 September 2020

Check for updates

(C) Author(s) (or their employer(s)) 2020. Re-use permitted under CC BY-NC. No commercial re-use. See rights and permissions. Published by BMJ.

${ }^{1}$ Department of Experimental and Clinical Medicine, University of Florence, Florence, Italy

${ }^{2}$ Department of Internal

Medicine and Geriatrics,

Fondazione Poliambulanza Istituto Ospedaliero, Brescia,

Lombardy, Italy

${ }^{3}$ Department of

Cardiothoracovascular Medicine, Careggi Hospital, Florence, Italy ${ }^{4}$ Department of Internal and Emergency Medicine, Careggi Hospital, Florence, Italy

${ }^{5}$ Intensive Care Unit and Regional ECMO Referral Center, Careggi Hospital, Florence, Italy

Correspondence to

Dr Niccolò Marchionni;

niccolo.marchionni@unifi.it

\section{ABSTRACT}

Objectives Several physiological abnormalities that develop during COVID-19 are associated with increased mortality. In the present study, we aimed to develop a clinical risk score to predict the in-hospital mortality in COVID-19 patients, based on a set of variables available soon after the hospitalisation triage.

Setting Retrospective cohort study of 516 patients consecutively admitted for COVID-19 to two Italian tertiary hospitals located in Northern and Central Italy were collected from 22 February 2020 (date of first admission) to 10 April 2020.

Participants Consecutive patients $\geq 18$ years admitted for COVID-19.

Main outcome measures Simple clinical and laboratory findings readily available after triage were compared by patients' survival status ('dead' vs 'alive'), with the objective of identifying baseline variables associated with mortality. These were used to build a COVID-19 in-hospital mortality risk score (COVID-19MRS).

Results Mean age was $67 \pm 13$ years (mean $\pm S D$ ), and $66.9 \%$ were male. Using Cox regression analysis, tertiles of increasing age ( $\geq 75$, upper vs $<62$ years, lower: HR 7.92; $p<0.001$ ) and number of chronic diseases ( $\geq 4$ vs $0-1$ : HR 2.09; $p=0.007$ ), respiratory rate (HR 1.04 per unit increase; $p=0.001$ ), $\mathrm{PaO}_{2} / \mathrm{FiO}_{2}$ (HR 0.995 per unit increase; $\mathrm{p}<0.001)$, serum creatinine (HR 1.34 per unit increase; $\mathrm{p}<0.001)$ and platelet count (HR 0.995 per unit increase; $\mathrm{p}=0.001$ ) were predictors of mortality. All six predictors were used to build the COVID-19MRS (Area Under the Curve $0.90,95 \% \mathrm{Cl} 0.87$ to 0.93 ), which proved to be highly accurate in stratifying patients at low, intermediate and high risk of in-hospital death $(p<0.001)$.

Conclusions The COVID-19MRS is a rapid, operatorindependent and inexpensive clinical tool that objectively predicts mortality in patients with COVID-19. The score could be helpful from triage to guide earlier assignment of COVID-19 patients to the most appropriate level of care.

\section{INTRODUCTION}

The first human cases of SARS-CoV-2 were reported in Wuhan, Hubei Province, China in January $2020^{12}$; subsequently, it spread worldwide, officially being defined as a

\section{Strengths and limitations of the study}

- Risk assessment tools readily available since the triage phase of COVID-19 are lacking

- Age, previous chronic diseases, respiratory rate, $\mathrm{PaO}_{2} / \mathrm{FiO}_{2}$, creatinine and platelet count were predictors of risk of in-hospital death.

- All six predictors were used to build a novel COVID-19 clinical risk score that proved to be highly accurate in stratifying patients at low, intermediate and high risk of death.

- Retrospective design; novel score to be validated in other, external, COVID-19 case series.

pandemic by WHO on 11 March $2020 .^{3-5}$ Italy was the first country outside Asia to be heavily affected by the virus, with a total of 189973 confirmed cases as of 23 April 2020. The Lombardy Region had the highest burden of mortality and strain on its healthcare system. ${ }^{6}$ However, a substantial reorganisation of healthcare facilities was necessary in all Italian regions to cope with the widespread and rapid increase in COVID-19 patient flow to emergency departments.

Prompt referral to the appropriate care setting (ie, low vs intermediate or high intensity) is of crucial importance to improve outcomes and healthcare resource utilisation. ${ }^{7-9}$ Given the high number of patients to be triaged during this emergency and the relative shortage of hospital beds, the availability of a disease-specific mortality risk score since initial triage might have been useful in identifying the appropriate level of care and reducing delay. However, there is a lack of reliable prognostic prediction models and, at present, no tool for the early stratification of mortality risk has been fully identified. ${ }^{10}$ A recent systematic review of prediction models concluded that the performance 
of prognostic estimates for COVID-19 may be overoptimistic and misleading, because of the high risk of bias in patient selection, unclear outcome definition and length of follow-up. ${ }^{10}$ Recently, clinical scores to predict the occurrence of critical illness and/or fatal outcome during COVID-19 were developed in a cohort of Chinese patients belonging to more than 500 centres throughout the country. ${ }^{11}{ }^{12}$ However, these were developed in a specific region which could potentially limit the generalisability of the risk score to other areas of the world.

Therefore, the aim of the present study was to develop a novel COVID-19 in-hospital mortality risk score (hereafter referred to as COVID-19MRS), based on data rapidly obtainable soon after hospital admission. To this end, we analysed a consecutive series of COVID-19 patients admitted to two tertiary care hospitals located in Northern and Central Italy.

\section{METHODS}

\section{Study design}

In this cohort study, we retrospectively reviewed the clinical history, laboratory and instrumental variables of all patients aged $\geq 18$ years diagnosed with COVID$19,{ }^{13}$ admitted to two Italian tertiary hospitals located in Northern and Central Italy (Poliambulanza Hospital, Brescia; and Careggi University Hospital, Florence) from 22 February 2020 (date of first admission in Brescia) to 10 April 2020, in order to identify a set of early predictors of mortality and build a mortality risk stratification score. The overall capacity of the two hospitals is about 1800 beds. The number of beds dedicated to COVID-19 patients progressively increased with the diffusion of the epidemic to a peak capacity of $655(228 / 1200$ in Careggi University Hospital and 427/600 in Poliambulanza Hospital; overall, 110 high-intensity care beds at peak).

\section{Study population data source}

A wide range of variables assessed on hospital admission were collected for each patient from electronic charts: these included demographics, number of drugs prescribed prior to admission, cardiovascular (CV) risk factors (eg, history of cigarette smoking, hypertension and diabetes), as well as data on previous chronic comorbidities (eg, CV and pulmonary diseases, cancer, depression and dementia). Functional status 2 weeks prior to hospitalisation was also assessed using the Barthel Index, in which lower values correspond to poorer function. ${ }^{14}$ Arterial blood gases, white blood cell count, lymphocyte and platelet (PLT) counts, alanine aminotransferase and aspartate aminotransferase, creatinine, creatine phosphokinase, lactate dehydrogenase (LDH) and high-sensitivity $\mathrm{C}$ reactive protein (CRP) were collected in all patients. Chest X-ray was also collected whenever deemed clinically indicated. Reading and interpretation of the main chest X-ray features was performed according to radiology guidelines. ${ }^{15}$ Information on respiratory support and drugs prescribed during hospital stay were recorded. Six medical doctors (CF, MV, MC, FC, GC and FM) selectively extracted all variables from electronic charts and transferred them into a unique database and independently reviewed them for their consistency. Data were last updated on 10 April 2020.

In keeping with statements by the Italian Regulatory Authorities (https://www.garanteprivacy.it/web/guest/ home/docweb/-/ docweb-display/docweb/5805552), Ethical Committees of both hospitals (Comitato Etico Area Vasta Centro, Careggi University Hospital, Florence and Comitato Etico Fondazione Poliambulanza Hospital, Brescia, Italy) approved data collection and granted a waiver of informed consent from study participants. Patients' identity was anonymised, and information protected by password.

\section{Study outcome}

Definition of an in-hospital all-cause mortality risk score based on simple, readily available clinical and laboratory findings.

\section{Patient and public involvement}

Patients or the public were not involved in the design or conduct of our research, partially due to its retrospective nature. Public Health Authorities will be involved in the upcoming, large-scale validation of the newly presented score.

\section{Statistical analysis and mortality risk score derivation}

Continuous variables were reported as mean $\pm \mathrm{SD}$ or as median with IQR, respectively, for normal and nonnormal distributions, whereas categorical variables were presented as counts and percentages. All variables were compared by survival status ('dead' vs 'alive') and patients still hospitalised at study closure were considered alive together with those who had been discharged during the study period. For continuous variables, comparisons were performed using t-test, analysis of variance or nonparametric tests, as appropriate. Categorical variables were compared with $\chi^{2}$ test, or Fisher's exact test when any expected cell count was less than 5 .

In accordance with the aim of the study, only data obtained shortly after initial triage were taken into account to build the mortality risk score. Cox multivariate regression analyses (with backward stepwise elimination) were calculated to identify baseline characteristics independently associated with the outcome, with inclusion of variables ( $<<0.10$ by univariate analysis) which were available for all patients. A two-sided $\mathrm{p}<0.05$ was considered statistically significant.

All continuous variables which were significantly associated with mortality by multivariate analysis were divided into tertiles and each of them was then scored from 1 to 3 to quantify the increasing mortality risk. Values obtained were then summed up to produce the mortality risk score whose predictive accuracy was tested using receiver operating characteristic (ROC) analysis. The mortality risk score was further divided into tertiles in order to identify 
Table 1 Demographic and clinical characteristics on hospital admission

\begin{tabular}{|c|c|c|c|c|}
\hline & Overall $(\mathrm{N}=516)$ & Dead $(N=120)$ & Alive $(\mathrm{N}=396)$ & $P$ value \\
\hline \multicolumn{5}{|l|}{ Demographic characteristics } \\
\hline Age, years, mean $\pm S D$ & $67 \pm 13$ & $79 \pm 8$ & $64 \pm 12$ & $<0.001$ \\
\hline$<62, \mathrm{~N}(\%)$ & $177(34.3)$ & $7(5.8)$ & $170(42.9)$ & \\
\hline $62-74, \mathrm{~N}(\%)$ & $171(33.1)$ & $27(22.5)$ & $144(36.4)$ & \\
\hline Hospital stay, median (IQR) & $9(5-14)$ & $6(3-10)$ & $10(6-15)$ & $<0.001$ \\
\hline Gender (male), N (\%) & $345(66.9)$ & $85(70.8)$ & $260(65.7)$ & 0.321 \\
\hline Smoking history, N (\%) & $112(21.7)$ & $26(21.7)$ & $86(21.7)$ & 0.999 \\
\hline Hypertension, N (\%) & $182(35.3)$ & $65(55.6)$ & $117(29.6)$ & $<0.001$ \\
\hline Diabetes mellitus, N (\%) & $161(31.4)$ & $51(43.6)$ & $110(27.8)$ & $<0.001$ \\
\hline Cancer, N (\%) & $50(9.7)$ & $23(19.2)$ & $27(6.8)$ & $<0.001$ \\
\hline Depression, N (\%) & $52(20.1)$ & $20(17.1)$ & $32(8.1)$ & 0.005 \\
\hline Dementia, N (\%) & $18(3.4)$ & $12(10.0)$ & $6(1.5)$ & $<0.001$ \\
\hline Comorbidities* mean \pm SD & $2.1 \pm 1.7$ & $3.2 \pm 1.9$ & $1.8 \pm 1.6$ & $<0.001$ \\
\hline$\geq 3, N(\%)$ & $179(34.7)$ & $68(58.1)$ & $111(28.2)$ & $<0.001$ \\
\hline Barthel Index, mean \pm SD & $85 \pm 28$ & $77 \pm 27$ & $94 \pm 13$ & $<0.001$ \\
\hline ACE-i/ARBs, N (\%) & $144(27.9)$ & $35(29.2)$ & $109(27.5)$ & 0.725 \\
\hline Drugs, N (\%) & $3.4 \pm 3.3$ & $5.6 \pm 3.5$ & $2.7 \pm 2.7$ & $<0.001$ \\
\hline \multicolumn{5}{|l|}{ Signs and symptoms } \\
\hline Diarrhoea, N (\%) & $47(9.2)$ & $10(8.3)$ & $37(9.4)$ & 0.782 \\
\hline Syncope, N (\%) & $27(5.2)$ & $11(9.2)$ & $16(4.1)$ & 0.023 \\
\hline Altered mental status, $\mathrm{N}(\%)$ & $24(4.7)$ & $12(10.0)$ & $12(3.0)$ & $<0.001$ \\
\hline
\end{tabular}

${ }^{*}$ Comorbidities are a composite variable including from hypertension to dementia. Percentages in brackets are calculated for numbers in columns for all dichotomous variables.

ACE-i, ACE inhibitors; ARBs, angiotensin receptor blockers; COPD, chronic obstructive pulmonary disease; CV, cardiovascular; TIA, transient ischaemic attack.

low-risk, intermediate-risk and high-risk categories, and assessed using Cox multivariate analysis. The KaplanMeier estimation method was computed to assess the probability of survival in patients in the different risk groups (low, intermediate and high) and compared using the log-rank test.

Analyses were performed using the SPSS V.26.0 statistical software package for Macintosh.

\section{RESULTS}

Regional trend and clinical characteristics on hospital admission

During the study period, 516 consecutive patients (301 in Brescia and 215 in Florence) diagnosed with COVID-19 were included in the study (table 1). According to date of admission, Brescia hospital anticipated both the first case (February 22 vs 25) and the peak of admissions by an average of 3 days, with a remarkably higher total and peak burden of admissions.

As of April 10, 314 (61\%) patients had been discharged from hospital $(273(87 \%)$ at home and $41(13 \%)$ to postacute facilities), $82(16 \%)$ were still hospitalised, while $120(23.2 \%)$ had died. Notably, no death occurred on the day of admission.

The mean age was $67 \pm 13$ years (range 21-95) and $345(66.9 \%)$ patients were male. Demographic and clinical characteristics of non-survivors and survivors are reported in table 1 . Non-survivors were significantly 
older ( $79 \pm 8$ vs $64 \pm 12$ years, $\mathrm{p}<0.001)$. Indeed, in-hospital fatality rate sharply increased with age and was more than five times higher in individuals aged $\geq 75$ years $(51.2 \%$ vs $<75$ years $9.8 \% ; \mathrm{p}<0.001)$. Conversely, prognosis was similar for both genders. The median hospital stay was 9 (IQR 5-14) days, significantly longer in survivors. Nonsurvivors also presented with a higher prevalence of $\mathrm{CV}$ risk factors, a greater burden of chronic comorbidities, and were more functionally impaired as indicated by a lower Barthel Index Score (table 1). Previous use of ACE inhibitors or angiotensin receptor blockers was similar in both groups while, in accordance with their higher burden of comorbidities, non-survivors reported a greater number of drugs chronically assumed prior to hospitalisation. The majority of patients presented with fever $(89.1 \%)$ and/or cough (57.3\%). Of note, non-survivors reported cough less frequently $(48.5 \%$ vs $59.8 \% ; \mathrm{p}=0.032$ ), but had a significantly higher prevalence of insomnia, syncope or altered mental status. While the prevalence of dyspnoea was similar in both groups (overall, $48.9 \%$ ), respiratory rate on admission was higher in non-survivors than in survivors $(26 \pm 7$ vs $21 \pm 6$ breaths/min; $\mathrm{p}<0.001$ ).

\section{Laboratory and imaging findings}

Nasopharyngeal swab was positive in 499 (97\%) patients. In the remaining patients, initially suspected diagnosis was confirmed by subsequent swabs, sputum or bronchoalveolar lavage. Laboratory findings are presented in table 2. In the entire population, median $\mathrm{PaO}_{2} / \mathrm{FiO}_{2}$ ratio was 269 (IQR 217-319), and values $<200$ were significantly associated with the probability of death. Lymphocytopaenia was present in $61 \%$ of the population, more frequently among non-survivors than survivors $(71 \%$ vs $58 \%$; $\mathrm{p}=0.011$ ), who also had lower PLT count and higher serum creatinine. CRP and LDH were increased in both groups and higher in non-survivors. Chest X-ray was abnormal in $>95 \%$ of cases, with a trend towards a higher prevalence of interstitial or mixed (both interstitial and consolidation) patterns in deceased patients.

\section{Medical management and clinical outcomes}

Non-survivors required non-invasive (continuous positive airway pressure and biphasic positive airway pressure modes) or invasive ventilation more frequently than survivors (table 3 ). While antibiotics were prescribed more frequently to non-survivors, heparin, hydroxychloroquine,

\begin{tabular}{|c|c|c|c|c|}
\hline & Overall $(\mathrm{N}=516)$ & Dead $(\mathrm{N}=120)$ & Alive $(\mathrm{N}=396)$ & $P$ value \\
\hline \multicolumn{5}{|l|}{ Laboratory findings } \\
\hline $\mathrm{PaO}_{2} / \mathrm{FiO}_{2}$, median (IQR) & $269(217-319)$ & $226(169-271)$ & $281(232-335)$ & $<0.001$ \\
\hline$<200, N(\%)$ & $101(19.6)$ & $42(35.0)$ & $59(15.0)$ & $<0.001$ \\
\hline$\geq 200, N(\%)$ & $415(80.4)$ & $78(65.0)$ & $337(85.1)$ & \\
\hline Haematocrit, \% median (IQR) & $41(38-44)$ & $39(35-43)$ & $42(39-44.75)$ & $<0.001$ \\
\hline Haemoglobin, g/L median (IQR) & $130(117-143)$ & $129(117-141)$ & $133(122-143)$ & 0.203 \\
\hline WBC, $\left(\times 10^{9} / \mathrm{L}\right)$ median (IQR) & $6.31(5-9)$ & $7.11(5-10.23)$ & $6(4.98-8.47)$ & 0.009 \\
\hline Lymphocytes, $\left(\times 10^{9} / \mathrm{L}\right)$ median (IQR) & $0.90(0.70-1.24)$ & $0.77(0.70-1.07)$ & $0.90(0.70-1.24)$ & $<0.001$ \\
\hline Lymphocytopaenia, N (\%) & $316(61)$ & $85(71)$ & $231(58)$ & 0.011 \\
\hline Platelets, $\left(\times 10^{9} / \mathrm{L}\right)$ median (IQR) & $182(142-234)$ & $156(117-218)$ & $187(152-238)$ & 0.001 \\
\hline ALT, U/L median (IQR) & $31(19-51)$ & $26(16-42)$ & $32(19-58)$ & 0.004 \\
\hline AST, U/L median (IQR) & $46(30-69)$ & $50(35-71)$ & $45(28-69)$ & 0.181 \\
\hline Serum creatinine, mg/dL median (IQR) & $0.94(0.79-1.22)$ & $1.23(0.92-1.91)$ & $0.90(0.79-1.13)$ & $<0.001$ \\
\hline CPK, U/L median (IQR) & $110(64-228)$ & $130(60-208)$ & $108(64-208)$ & 0.085 \\
\hline LDH, U/L median (IQR) & $351(268-480)$ & $473(338-610)$ & $335(266-437)$ & $<0.001$ \\
\hline CRP, mg/L median (IQR) & $94(44.3-161.8)$ & $138(85-188)$ & $77(37-152)$ & $<0.001$ \\
\hline Imaging & $\mathrm{N}=486$ & $\mathrm{~N}=114$ & $\mathrm{~N}=372$ & \\
\hline \multicolumn{5}{|l|}{ Chest X-ray } \\
\hline Negative, N (\%) & $20(4.1)$ & $2(1.8)$ & $18(4.8)$ & 0.053 \\
\hline Consolidation, N (\%) & $67(13.8)$ & $12(10.5)$ & $55(14.8)$ & \\
\hline Interstitial, N (\%) & $346(71.2)$ & $81(71.1)$ & $265(71.2)$ & \\
\hline Mixed, N (\%) & $53(10.9)$ & $19(16.7)$ & $34(9.1)$ & \\
\hline
\end{tabular}

Percentages in round brackets are calculated for numbers in columns for all dichotomous variables

ALT, alanine aminotransferase; AST, aspartate aminotransferase; CPK, creatine phosphokinase; CRP, C reactive protein; LDH, lactate dehydrogenase; WBC, white blood cell count. 
Table 3 Treatment strategies

\begin{tabular}{lcccc}
\hline & Overall (N=516) & Dead (N=120) & Alive (N=396) & P value \\
\hline Respiratory support & & & & \\
$\quad$ None, N (\%) & $57(11.0)$ & $2(1.7)$ & $55(13.9)$ & $<0.001$ \\
\hline Oxygen, N (\%) & $334(64.7)$ & $78(65.0)$ & $256(65.1)$ & \\
Non-invasive ventilation, N (\%) & $65(12.6)$ & $23(19.2)$ & $42(10.6)$ & \\
$\quad$ Invasive ventilation, N (\%) & $60(11.6)$ & $17(14.2)$ & $43(10.9)$ & \\
Drugs & & & $301(76.0)$ & 0.003 \\
$\quad$ Antibiotics, N (\%) & $407(78.9)$ & $106(88.3)$ & $242(61.1)$ & 0.008 \\
Heparin, N (\%) & $299(57.9)$ & $57(47.5)$ & $225(56.8)$ & $<0.001$ \\
Hydroxychloroquine, N (\%) & $268(51.9)$ & $43(35.8)$ & $208(52.5)$ & $<0.001$ \\
\hline Lopinavir/ritonavir, N (\%) & $247(50.7)$ & $39(32.5)$ & $131(33.1)$ & 0.371 \\
\hline Corticosteroids, N (\%) & $176(34.1)$ & $45(37.5)$ & $54(13.6)$ & $<0.001$ \\
\hline Monoclonal antibodies, N (\%) & $57(11.3)$ & $3(2.5)$ & &
\end{tabular}

antiviral agents (combination of lopinavir/ritonavir) and monoclonal antibodies (mAbs, tocilizumab) were prescribed more frequently to survivors. In contrast, corticosteroid therapy was adopted in similar proportions in the two groups. Patients receiving $\mathrm{mAbs}$ were younger $(65 \pm 9$ vs $68 \pm 14$ years, $\mathrm{p}<0.01)$ and had lower serum creatinine $(0.9 \pm 0.3$ vs $1.2 \pm 0.9 \mathrm{mg} / \mathrm{dL}, \mathrm{p}=0.024)$.

\section{Predictors of mortality and development of the mortality risk} score

At Cox multivariate regression analysis (table 4), age, number of chronic comorbidities, respiratory rate and serum creatinine emerged as positive predictors, while $\mathrm{PaO}_{2} / \mathrm{FiO}_{2}$ ratio and PLT count were negative predictors of death. Online supplemental table 1 summarises all

Table 4 Cox multivariable regression analyses of determinants of in-hospital mortality

\begin{tabular}{|c|c|c|c|}
\hline Variables & HR & $95.0 \% \mathrm{Cl}$ & $P$ value \\
\hline \multicolumn{4}{|l|}{ Age (tertiles) } \\
\hline $62-74$ versus $<62$ years & 2.86 & 1.23 to 6.64 & 0.014 \\
\hline$\geq 75$ versus $<62$ years & 7.92 & 3.60 to 17.43 & $<0.001$ \\
\hline \multicolumn{4}{|c|}{ Number of comorbidities (tertiles) } \\
\hline $2-3$ versus $0-1$ & 1.85 & 1.11 to 3.08 & 0.018 \\
\hline$\geq 4$ versus $0-1$ & 2.09 & 1.23 to 3.55 & 0.007 \\
\hline $\begin{array}{l}\text { Respiratory rate (breaths/ } \\
\text { min), for unit increase }\end{array}$ & 1.04 & 1.02 to 1.07 & 0.001 \\
\hline $\begin{array}{l}\mathrm{PaO}_{2} / \mathrm{FiO}_{2} \text {, for unit } \\
\text { increase }\end{array}$ & 0.995 & 0.992 to 0.997 & $<0.001$ \\
\hline $\begin{array}{l}\text { Creatinine }(\mathrm{mg} / \mathrm{dL}) \text {, for unit } \\
\text { increase }\end{array}$ & 1.34 & 1.18 to 1.51 & $<0.001$ \\
\hline $\begin{array}{l}\text { Platelets }\left(10^{9} / \mathrm{L}\right) \text {, for unit } \\
\text { increase }\end{array}$ & 0.995 & 0.992 to 0.998 & 0.001 \\
\hline
\end{tabular}

History of cardiovascular disease, hypertension, diabetes, depression, dementia and cancer were included into 'comorbidities'. Variables excluded ( $p>0.10$ ) from both models: No. of drugs, Barthel Index, C reactive protein. candidate variables that were excluded by stepwise backward deletion. Interestingly, preadmission functional status as assessed by Barthel Index and the number of drugs previously assumed were excluded from the model.

Variables included in the model (table 4) were used to calculate the mortality risk score intended for rapid patient's risk assessment on hospital admission. In this regard, age, number of comorbidities, respiratory rate, $\mathrm{PaO}_{2} / \mathrm{FiO}_{2}$, serum creatinine and PLT count reclassified into tertiles were used to build the mortality risk score with identification of three risk strata as reported in table 5. ROC analysis performed on the clinical risk score yielded an Area Under the Curve (AUC) of 0.90 (online supplemental figure 1, 95\% CI 0.87 to 0.93). KaplanMeier survival analysis developed using the tertiles of the clinical score showed an excellent stratification of risk (figure 1; intermediate-risk vs low-risk HR: 4.134, 95\% CI 1.725 to 9.905 ; high-risk vs low-risk HR: 22.173 , $95 \%$ CI 9.681 to $50.783, \mathrm{p}<0.001)$. A cut-off score of $\leq 8$ identified a subset of $63(12.2 \%)$ patients without fatalities during the study period, which therefore may be defined as 'at very low risk'.

\section{DISCUSSION}

In this study, we developed the COVID-19MRS that was shown to be able to stratify the risk of in-hospital death in COVID-19 patients since their admission. This score includes a composite of six objective, operatorindependent variables (age, number of chronic comorbidities, respiratory rate, $\mathrm{PaO}_{2} / \mathrm{FiO}_{2}$, serum creatinine and platelet count) usually available within a couple of hours after hospitalisation. The score identified three categories at increasing risk of death with a high level of accuracy. The scoring process suggests that, while lowrisk patients may be assigned safely to low-intensity care, higher intensity wards should be alerted during triage for the intermediate-risk and high-risk patients. Moreover, the score seems to allow for the identification of about 
Table 5 Variables and relative scores to calculate the COVID-19 clinical risk score

\begin{tabular}{|c|c|c|c|c|c|c|c|c|c|c|c|c|}
\hline $\begin{array}{c}\text { Age } \\
\text { (years) }\end{array}$ & Score & $\begin{array}{c}\text { Comorbidities } \\
\text { (N) }\end{array}$ & Score & $\begin{array}{c}\mathrm{RR} \\
\text { (breaths/min) } \\
\end{array}$ & Score & $\mathrm{PaO}_{2} / \mathrm{FiO}_{2}$ & Score & $\begin{array}{c}\text { Creatinine } \\
\text { (mg/dL) }\end{array}$ & Score & $\begin{array}{c}\text { Platelet } \\
\text { count }\left(10^{9} / \mathrm{L}\right)\end{array}$ & Score & $\begin{array}{c}\text { Risk categories } \\
\text { (sum of individual } \\
\text { variable scores) }\end{array}$ \\
\hline$<62$ & 1 & $\leq 1$ & 1 & $\leq 20$ & 1 & $>300$ & 1 & $<0.83$ & 1 & $>212$ & 1 & Low $\leq 10$ \\
\hline$\geq 75$ & 3 & $\geq 4$ & 3 & $\geq 25$ & 3 & $<236$ & 3 & $\geq 1.13$ & 3 & $<156$ & 3 & High risk $\geq 14$ \\
\hline
\end{tabular}

Categories represent the tertile distribution of each variable.

$10 \%-15 \%$ of 'very low-risk' patients (score $\leq 8$ ) with no events who, though symptomatic for proven COVID-19, might be immediately discharged home, with the sole indication to health status monitoring.

Performance of prognostic estimates for COVID-19 is under scrutiny as thought to be over optimistic and misleading, because of the high risk of bias in patient selection. ${ }^{10}$ As a case in point, a score based on a large cohort of COVID-19 patients in China found that age was associated with greater risk of death. ${ }^{11}$ However, the mean age of this cohort was $49 \pm 16$ years, which is $15-20$ years less than observed in most European and US studies published to date. Although apparently similar in terms of objectives, we stratified the risk of death in a consecutive cohort of patients who shared demographic and clinical characteristics similar to other European and US studies. ${ }^{3-5}$ We, therefore, believe that our COVID-19MRS may hold potential generalisability for other countries. The early identification of patients at risk of clinical deterioration and death is of primary importance, considering that median interval from hospital admission to the Intensive Care Unit (ICU) is around 3 days ${ }^{16}$. Given that our proposed score is predictive of mortality based on six inexpensive, operator-independent and rapidly obtainable parameters, it could help clinicians to identify highrisk patients with poor prognosis since the triage phase.
One in four patients in our cohort of Italian COVID-19 cases died and age was the strongest driver of an adverse outcome. In fact, compared with patients younger than 62 years of age, the risk of death was almost three and eight times higher in individuals $62-74$ and $75+$ years of age, respectively. Such an exponential risk growth persisted after adjusting for burden of comorbidities and a series of clinical characteristics. Such a strong association between older age and prognosis has been observed in previous studies on COVID-19 both in China and in other countries, although with a less rapid increase in age-specific risk. ${ }^{17}$ This difference could be attributed to the lower median age reported in those studies and to the fact that we explored a wider age range (21-95 years), with one-third of our population above the age of $75 .{ }^{17}{ }^{18} \mathrm{In}$ COVID-19, age has been associated with variable degrees of increasing risk of admissions to ICU, onset of acute respiratory distress syndrome, myocardial damage and fatal outcome. ${ }^{16-22}$ This observation also holds true for previous epidemic or pandemic outbreaks, such as SARS and Middle East respiratory syndrome where, as in COVID-19, the respiratory system is both the entry route and the main target of viral infection. ${ }^{23}{ }^{24}$ We could argue that lung senescence, resulting in decreased elasticity, increased end-expiratory lung volume and disrupted alveolar integrity, ${ }^{25}$ together with kidney senescence, ${ }^{26}$

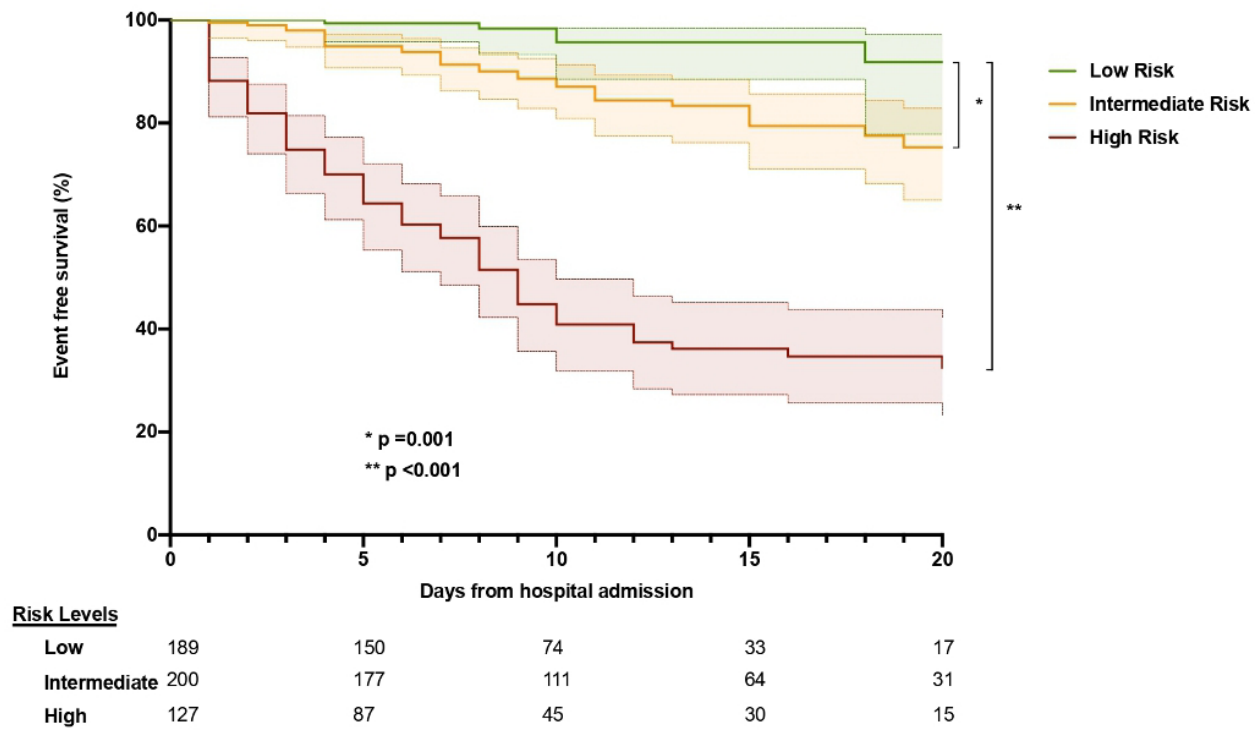

Figure 1 Kaplan-Meier analysis of overall survival of patients diagnosed with COVID-19 according to three risk categories. Shaded areas represent lower and upper $95 \% \mathrm{Cls}$. 
may predispose per se to SARS-CoV-2-related acute respiratory and renal failure even in otherwise relatively robust elderly individuals. This hypothesis is consistent with the observation that age and three functional indicators of target organs (respiratory rate, $\mathrm{PaO}_{2} / \mathrm{FiO}_{2}$ and serum creatinine) emerged as independent predictors of in-hospital mortality, after adjusting for comorbidities.

The observation of the highly negative impact of age suggests that in the absence of specifically effective drug therapy and vaccination, ${ }^{27}$ social isolation and the prevention of infecting contacts are key issues particularly relevant in individuals aged $70-75$ years and over. These data may represent a call to action for health authorities, in order to update management policies in the community in general and in nursing homes in particular, where in fact the highest mortality rates occurred in Italy and in other countries. ${ }^{28}$

While a low PLT count was frequently observed in nonsurvivor COVID-19 patients, ${ }^{16} 192229$ in our cohort, lower values were directly associated with adverse outcome, suggesting a possible role of COVID-19-related coagulopathy in determining a poor outcome. ${ }^{30} 31$

Present therapeutic recommendations on COVID-19 have a limited level of evidence, ${ }^{32}$ and have evolved during progression of the pandemic wave. Most of our patients received oxygen or mechanical ventilation support and antibiotics; conversely one in two patients were treated by antiviral and/or anti-inflammatory drugs. Given the nature of our study, we are unable to draw any firm conclusions regarding treatment efficacy, as specific analyses would be required, which were beyond the scope of the present work.

Some limitations of our study have to be acknowledged. First, the retrospective and observational nature of our analysis does not allow us to draw any firm conclusions about therapeutic strategies. Second, some laboratory parameters, which proved to be of prognostic relevance in other studies, ${ }^{1922}$ were not collected for all individuals in our sample, possibly due to the different degrees of severity of patients (ie, very mildly affected vs critically ill patients at presentation). Therefore, we cannot rule out that variables excluded from the scoring system would have had a significant impact on mortality prediction. However, consistent with our purpose, we considered variables only available soon after admission. Third, since nasopharyngeal swabs were our key criterion for SARS-CoV-2 detection, we did not assess viremia, while the correlation of viral load with disease severity is still a matter of debate. Moreover, case ascertainment methodological bias, which may impact on patient selection and outcome, cannot be excluded as partial explanation for the findings observed. Indeed, the vast majority of patients included in the present analysis had a positive RT-PCR on first testing and only in a minority of cases was sputum or bronchoalveolar lavage needed to confirm the infection. Fourth, $82(15.9 \%)$ out of 516 patients were still in-hospital at the time of closure of follow-up. Nevertheless, after excluding these patients from our analysis, results were fully confirmed, with a 0.90 AUC of the predictive score (data not shown). Finally, we do not have information regarding the time span between symptom onset and admission, which might have had an impact on either clinical or laboratory parameters that we sampled on hospital admission.

In conclusion, we developed a scoring system (COVID19MRS) that objectively and accurately predicts in-hospital mortality COVID-19 patients. This score, simply based on age, number of chronic comorbidities, respiratory rate, $\mathrm{PaO}_{2} / \mathrm{FiO}_{2}$, serum creatinine and platelet count, is a rapid and inexpensive clinical tool, which could be helpful for earlier identification of in-hospital mortality risk and, hence, assignment to the appropriate level of care and treatment of COVID-19 patients. Studies in clinical series different from ours are needed to validate the present scoring system.

Acknowledgements We thank Dr Colin Egan for his careful revision of the manuscript. We are grateful to'Fondazione A.R.Card Onlus' for its unconditional support.

Contributors CF and NM conceived the study, conducted data acquisition, management andanalysis, drafted and critically revised the manuscript and are accountable for all aspects of the work. RR, FL and RM contributed to conceive the study and critically revised the manuscript. MV conducted data acquisition, drafted and critically revised the manuscript, with the contribution of $F C, G C, F M$, and $M C$. $\mathrm{AB}, \mathrm{PF}, \mathrm{AM}, \mathrm{CN}, \mathrm{AP}, \mathrm{FP}, \mathrm{RP}, \mathrm{LP}$ and $\mathrm{AU}$ critically revised the manuscript for important intellectual content. SF contributed substantially to data analysis and to critical revision of the manuscript. All Authors read and approved the final manuscript.

Funding The authors have not declared a specific grant for this research from any funding agency in the public, commercial or not-for-profit sectors.

Competing interests None declared.

Patient and public involvement Patients and/or the public were not involved in the design, or conduct, or reporting, or dissemination plans of this research.

Patient consent for publication Not required.

Provenance and peer review Not commissioned; externally peer reviewed.

Data availability statement Deidentified participant data are stored in a University of Florence password protected in-house server

Open access This is an open access article distributed in accordance with the Creative Commons Attribution Non Commercial (CC BY-NC 4.0) license, which permits others to distribute, remix, adapt, build upon this work non-commercially, and license their derivative works on different terms, provided the original work is properly cited, appropriate credit is given, any changes made indicated, and the use is non-commercial. See: http://creativecommons.org/licenses/by-nc/4.0/.

\section{ORCID iDs}

Carlo Fumagalli http://orcid.org/0000-0001-7963-5049

Niccolò Marchionni http://orcid.org/0000-0002-8101-4695

\section{REFERENCES}

1 Wu F, Zhao S, Yu B, et al. A new coronavirus associated with human respiratory disease in China. Nature 2020;579:265-9.

2 Li Q, Guan X, Wu P, et al. Early transmission dynamics in Wuhan, China, of novel coronavirus-infected pneumonia. N Engl J Med 2020;382:1199-207.

3 Grasselli G, Zangrillo A, Zanella A, et al. Baseline characteristics and outcomes of 1591 patients infected with SARS-CoV-2 admitted to ICUs of the Lombardy region, Italy. JAMA 2020;323:1574-8.

4 Richardson S, Hirsch JS, Narasimhan M, et al. Presenting characteristics, comorbidities, and outcomes among 5700 patients hospitalized with COVID-19 in the new York City area. JAMA 2020;323:2052-9.

5 Helms J, Tacquard C, Severac F, et al. High risk of thrombosis in patients with severe SARS-CoV-2 infection: a multicenter prospective cohort study. Intensive Care Med 2020;46:1089-98. 
6 Buoro S, Di Marco F, Rizzi M, et al. Papa Giovanni XXIII Bergamo Hospital at the time of the COVID-19 outbreak: letter from the warfront.... Int J Lab Hematol 2020;42 Suppl 1:8-10.

7 Johnson DW, Schmidt UH, Bittner EA, et al. Delay of transfer from the intensive care unit: a prospective observational study of incidence, causes, and financial impact. Crit Care 2013;17:R128.

8 Churpek MM, Wendlandt B, Zadravecz FJ, et al. Association between intensive care unit transfer delay and hospital mortality: a multicenter investigation. J Hosp Med 2016;11:757-62.

9 Liu V, Kipnis P, Rizk NW, et al. Adverse outcomes associated with delayed intensive care unit transfers in an integrated healthcare system. J Hosp Med 2012.

10 Wynants L, Van Calster B, Collins GS, et al. Prediction models for diagnosis and prognosis of covid-19 infection: systematic review and critical appraisal. BMJ 2020;369:m1328.

11 Liang W, Liang $\mathrm{H}, \mathrm{Ou}$ L, et al. Development and validation of a clinical risk score to predict the occurrence of critical illness in hospitalized patients with COVID-19. JAMA Intern Med 2020;180:1081

12 Chen R, Liang W, Jiang M, et al. Risk Factors of Fatal Outcome in Hospitalized Subjects With Coronavirus Disease 2019 From a Nationwide Analysis in China. Chest 2020;158:97-105.

$13 \mathrm{WHO}$. Clinical management of severe acute respiratory infection when COVID-19 is suspected (v1.2, 2020: 1-21. https://www. who.int/publications-detail/clinical-management-of-severe-acuterespiratory-infection-when-novel-coronavirus-(ncov)-infection-issuspected

14 Mahoney FI, Barthel DW. Functional evaluation: the Barthel index. Md State Med J 1965;14:61-5.

15 Hansell DM, Bankier AA, MacMahon H, et al. Fleischner Society: glossary of terms for thoracic imaging. Radiology 2008;246:697-722.

16 Huang C, Wang Y, Li X, et al. Clinical features of patients infected with 2019 novel coronavirus in Wuhan, China. Lancet 2020;395:497-506.

17 Wu Z, McGoogan JM. Characteristics of and Important Lessons From the Coronavirus Disease 2019 (COVID-19) Outbreak in China: Summary of a Report of 72314 Cases From the Chinese Center for Disease Control and Prevention. JAMA 2020;323:1239-42.

18 The World Bank. World Bank Staff Estimates Based on Age/ Sex Distributions of United Nations Population Division's World
Population Prospects: 2019 Revision, 2019. Available: https://data. worldbank.org/indicator/SP.POP.65UP.TO.ZS

19 Wu C, Chen X, Cai Y, et al. Risk factors associated with acute respiratory distress syndrome and death in patients with coronavirus disease 2019 pneumonia in Wuhan, China. JAMA Intern Med 2020;180:934.

20 Guan W, Ni Z, Hu Y, et al. Clinical characteristics of coronavirus disease 2019 in China. N Engl J Med 2020:1-13.

21 Shi S, Qin M, Shen B, et al. Association of cardiac injury with mortality in hospitalized patients with COVID-19 in Wuhan, China. JAMA Cardiol 2020;5:802-8.

22 Zhou F, Yu T, Du R, et al. Clinical course and risk factors for mortality of adult inpatients with COVID-19 in Wuhan, China: a retrospective cohort study. Lancet 2020;395:1054-62.

23 Choi KW, Chau TN, Tsang O, et al. Outcomes and prognostic factors in 267 patients with severe acute respiratory syndrome in Hong Kong. Ann Intern Med 2003;139:715-24.

24 Hong $\mathrm{K}-\mathrm{H}$, Choi J-P, Hong S-H, et al. Predictors of mortality in middle East respiratory syndrome (MERS). Thorax 2018;73:286-9.

25 Bowdish DME. The aging lung: is lung health good health for older adults? Chest 2019;155:391-400.

26 O'Sullivan ED, Hughes J, Ferenbach DA. Renal aging: causes and consequences. J Am Soc Nephrol 2017;28:407-20.

27 Koff WC, Williams MA. Covid-19 and Immunity in Aging Populations - A New Research Agenda. N Engl J Med 2020;383:804-5.

28 WHO. Virtual press briefing on COVID-19: key considerations on nursing homes. WHO Regional Office for Europe, 2020. http://www. euro.who.int/en/media-centre/events/events/2020/04/virtual-pressbriefing-on-covid-19-key-considerations-on-nursing-homes

29 Chen T, Wu D, Chen H, et al. Clinical characteristics of 113 deceased patients with coronavirus disease 2019: retrospective study. BMJ 2020;368:m1091.

30 Bikdeli B, Madhavan M V, Jimenez D, et al. COVID-19 and thrombotic or thromboembolic disease: implications for prevention, antithrombotic therapy, and follow-up. J Am Coll Cardiol 2020:27284

31 Lippi G, Plebani M, Henry BM. Thrombocytopenia is associated with severe coronavirus disease 2019 (COVID-19) infections: a metaanalysis. Clin Chim Acta 2020;506:145-8.

32 Poston JT, Patel BK, Davis AM. Management of critically ill adults with COVID-19. JAMA 2020:E1-3. 